\title{
A Química Orgânica no Ensino Secundário: A Percepção dos Alunos
}

\author{
Sérgio C. Leal ${ }^{1,2,3, *}$, João Paulo Leal ${ }^{2,4}$, \\ Maria A. F. Faustino ${ }^{1}$, Artur M. S. Silva ${ }^{1}$
}

\begin{abstract}
Inicic niciou-se em número anterior deste Boletim a divulgação de um estudo realizado no âmbito do Mestrado em Ensino de Física e Química, que teve como intenção analisar as percepções de alunos e professores acerca da Química Orgânica abordada no ensino secundário (ES) com o propósito de, conhecendo a situação concreta da Química Orgânica no actual ES, apresentar propostas que visem a melhoria do processo ensino/aprendizagem das ciências e da Química Orgânica em particular. A presente comunicação complementa a anterior, onde foram analisados os programas curriculares das duas últimas reformas curriculares, manuais escolares e apresentada a percepção dos professores face aos conteúdos de Química Orgânica. Serão aqui apresentados os resultados e conclusões obtidas no respectivo estudo relativas às percepções dos alunos face ao estudo da Química Orgânica no ES. A percepção dos alunos do ES para com a Química Orgânica levanta questões interessantes e aponta caminhos a seguir, concretamente no sentido de mudar as práticas de ensino tradicionais e contextualizar a aprendizagem das ciências, em particular da Química Orgânica. Mostra também que a utilização das novas tecnologias de informação e da experimentação devem ser privilegiadas como recursos didácticos.
\end{abstract}

\section{Metodologia}

O estudo da percepção dos alunos foi realizado com base nas respostas a questionários feitos a 502 alunos do Agrupamento 1 - Curso Geral Científico-Natural e Cursos Tecnológicos (atendendo à actual reforma curricular, os alunos deste agrupamento pertencem à área de Ciências e Tecnologias do Curso Científico-Humanístico) - Tabela 1.

Foram inicialmente seleccionados 600 alunos de escolas secundárias do centro de área educativa (CAE) de Aveiro, representando cerca de 10\% do total de alunos, e 100 alunos que frequentavam o $1 .^{\circ}$ ano dos cursos de Ciências e Engenharias da Universidade de Aveiro, que serviram como grupo de alunos que havia concluído o ES.

Departamento de Química \& QOPNA, Universidade de Aveiro, 3810-193 Aveiro

Departamento de Química e Bioquímica, Faculdade de Ciências da Universidade de Lisboa, 1149-016 Lisboa Escola Secundária com $3 .^{\circ}$ ciclo Padre António Vieira, 1749-063 Lisboa

Unidade de Ciências Químicas e Radiofarmacêuticas, Instituto Tecnológico Nuclear, 2686-953 Sacavém

E-mail: sergioleal20@gmail.com
Tabela 1 - Número de questionários dirigidos a alunos do ES e universitário utilizados no presente estudo

\begin{tabular}{cc}
$\begin{array}{c}\text { Ano de } \\
\text { escolaridade }\end{array}$ & $\begin{array}{c}\text { N.@ de questionários } \\
\text { N.@ de alunos do } \\
\text { Gerupamento 1 - Curso } \\
\text { e Cursos Tecnológicos }\end{array}$ \\
\hline $10^{\circ}$ & 130 \\
$11^{\circ}$ & 115 \\
$12^{\circ}$ & 160 \\
ES completo & 97 \\
\hline Total: & 502 \\
\hline
\end{tabular}

Os inquéritos por questionário possuíam diversos tipos de resposta pelo que o seu tratamento foi diferenciado. As respostas seleccionadas dos inquéritos por questionário aplicados neste estudo [1], realizado no âmbito do Mestrado em Ensino de Física e Química [2], foram apresentadas em tabelas para as questões abertas, enquanto que para as questões fechadas se decidiu utilizar diagramas de Pareto e caixas de bigodes (bloxplot).

Os Diagramas de Pareto são "gráficos de barra" ordenados por número de frequência de respostas (do maior para o menor). Para melhor visualização, os gráficos 2 e 3 aparecem como gráficos de colunas.

\section{Resultados Obtidos}

A correlação encontrada no questionário dos alunos entre as variáveis estudadas foi muito elevada, e dada a extensão dos resultados ${ }^{1}$, apenas iremos apresentar alguns que se consideram mais significativos referentes às percepções dos alunos face ao estudo da Química Orgânica no ES.

\section{Alunos}

Após a caracterização da amostra (perfil académico), os alunos foram questionados sobre: "No seu entender o que é que estuda a Química Orgânica?". Para maior facilidade de análise das respostas dadas, estas foram agrupadas nas quatro categorias de resposta que se encontram na Tabela 2.

A análise dos dados revelou uma tendência, à medida que se progride no $E S$, para os alunos saberem o que estuda a Química Orgânica, inverten- 
do-se essa tendência nos alunos que haviam concluído o ES. Os alunos do $10 .^{\circ}$ ano de escolaridade são praticamente os únicos que referiram que não sabiam o que estuda a Química Orgânica, dando como justificação o facto de nunca terem estudado essa área da Química em nenhuma disciplina. O resultado mais estranho salientado pelo gráfico 1 resulta do facto de um número não desprezável de alunos do ensino universitário (EU) $(20 \%)$ indicar que não sabe o que estuda a Química Orgânica.

Tabela 2 - Categorias de resposta e respectiva codificação para a questão: "No seu entender o que é que estuda a Química Orgânica?"

\begin{tabular}{|c|l|}
\hline Código & \multicolumn{1}{|c|}{ Categoria de resposta } \\
\hline 1 & $\begin{array}{l}\text { Os alunos sabem o que estuda a } \\
\text { Química Orgânica². }\end{array}$ \\
\hline 2 & $\begin{array}{l}\text { Os alunos não especificam bem o } \\
\text { que estuda a Química Orgânica, } \\
\text { mas indicam exemplos ou situações } \\
\text { aplicadas ao tópico Química } \\
\text { Orgânica. }\end{array}$ \\
\hline 3 & $\begin{array}{l}\text { Os alunos referem que não sabem } \\
\text { o que estuda a Química Orgânica, } \\
\text { dado que nunca estudaram esse } \\
\text { tópico em nenhuma disciplina. }\end{array}$ \\
\hline 4 & $\begin{array}{l}\text { Os alunos não sabem o que estuda } \\
\text { a Química Orgânica. }\end{array}$ \\
\hline
\end{tabular}

Os alunos quando inquiridos sobre se acham o estudo da Química Orgânica interessante (Gráfico 2), apresentam uma tendência à medida que se progride no ES de acharem «razoavelmente» ou «muito» interessante o estudo da Química Orgânica.

Destacam-se os alunos do $10 .^{\circ}$ ano de escolaridade como aqueles que mais responderam que não sabiam se estudar Química Orgânica seria interessante $(9 \%)$, o que não é de estranhar, uma vez que muitos deles afirmam não ter estudado ainda Química Orgânica.

Contudo, quando os resultados são analisados em maior detalhe e se questiona os alunos se consideram importante estudar Química Orgânica, estes consideram tendencialmente «razoavelmente» ou «muito» interessante o estudo da Química Orgânica. No entanto, são os alunos do $10 .^{\circ}$ ano de escolaridade e os que haviam completado o ES que referem preferencialmente ser «muito interessante» o seu estudo, enquanto que os alunos do $11 .^{\circ}$ e $12 .^{\circ}$ ano de escolaridade consideraram ser «razoavelmente» interessante o seu estudo.

Quanto à questão "Sente-se motivado para a aprendizagem da Química Orgânica?", verifica-se uma ligeira tendência à medida que se progride no ES de os alunos referirem que se sentem «razoavelmente» motivados para a aprendizagem da Química Orgânica (a motivação para a aprendizagem da Química Orgânica diminui ao longo deste nível de ensino o que pode levar a perguntar qual o motivo desta diminuição). A mesma tendência ocorre nos alunos do EU inquiridos (Gráfico 3).

Os alunos referindo-se ao tipo de aulas que os seus professores de Química habitualmente realizam na abordagem da Química Orgânica em sala de aula, inferem que os seus professores da área de Química habitualmente realizavam «aulas teóricas com resolução de exercícios» em detrimento de aulas teóricas com exemplificação experimental ou aulas predominantemente de trabalho experimental. Verifica-se mais uma vez que os alunos do $10 .^{\circ}$ ano de escolaridade foram quem mais referiu $(10 \%)$ que nunca abordaram qualquer tópico de Química Orgânica nas aulas (Gráfico 4).

Quando a questão anterior se coloca aos alunos, mas agora relativamente às práticas lectivas dos seus professores das áreas de Biologia, os resultados obtidos e apresentados no gráfico 5 evidenciam uma tendência à medida que se progride no ES dos alunos referirem que os professores desta área disciplinar habitualmente realizam "aulas teóricas» na abordagem de tópicos de Química Orgânica.

Note-se que $22 \%$ dos alunos inquiridos que frequentavam o ES refere que nunca abordou qualquer tópico de Química Orgânica nas aulas da área de Biologia. Apenas os alunos que haviam concluído o ES tomaram consciência que abordaram conteúdos de Química Orgânica (Gráfico 5).

No gráfico 6 encontram-se apresentados os resultados obtidos sobre as dificuldades que os alunos dizem sentir em compreenderem aspectos relacionados com a Química Orgânica. Observa-se uma tendência, à medida que se progride no ensino, de os alunos referirem que sentem algumas dificuldades em compreenderem aspectos relacionados com a Química Orgânica. Mais uma vez, cerca de metade dos alunos do $10 .^{\circ}$ ano de escolaridade refere que «não sabem» se sentem dificuldades a Química Orgânica.

As principais razões apontadas para as dificuldades sentidas pelos alunos do ES em compreender aspectos relacionados com a Química Orgâni-

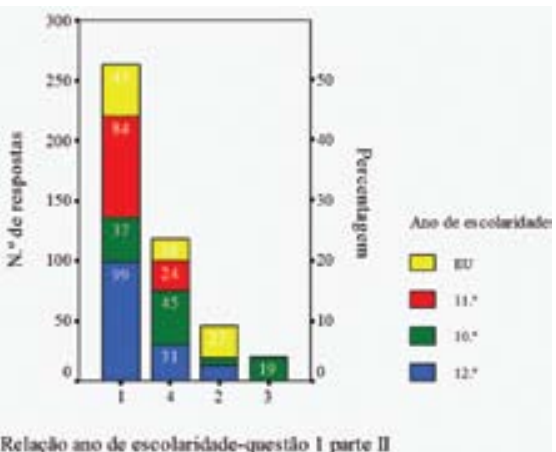

Gráfico 1 - Respostas à questão: "No seu entender o que é que estuda a Química Orgânica?"

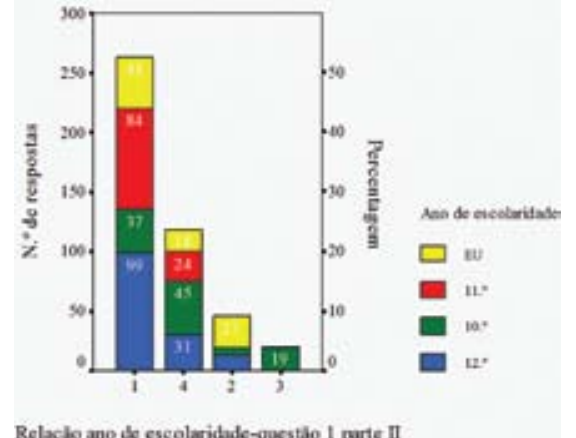

Gráfico 2 - Respostas à questão: "Acha o estudo da Química Orgânica interessante?"

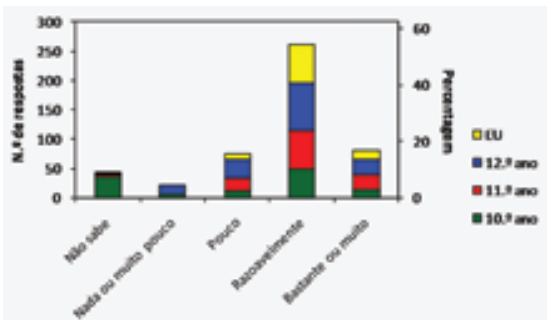

Gráfico 3 - Respostas à questão: "Sente-se motivado para a aprendizagem da Química Orgânica?" 
ca encontram-se apresentadas nos gráficos 7,8 e 9 e a dos alunos que haviam concluído o ES encontram-se apresentadas nos gráficos 10 e 11 . Este gráficos foram construídos com base na frequência de resposta quando responderam sentir «Nenhuma ou muito pouca» e «Razoável» dificuldade em compreender aspectos relacionados com a Química Orgânica, respectivamente. As principais causas apresentada pelos alunos do ES, que apresentam alguma ou muita dificuldade em compreender os aspectos relacionados com a Química Orgânica, são principalmente a falta de estudo e de interesse e só depois uma deficiente explicação por parte do professor. Curiosamente, e apesar destes serem os mesmos motivos invocados pelos alunos universitários (com o ES concluído) (Gráfico 11) que assumem ter razoável dificuldade com esta área, a frequência das respostas aponta o professor como o principal responsável pela dificuldades sentidas, seguida da falta de estudo. Em ambas as situações, quando as dificuldades sentidas em compreender os aspectos relacionados com a Química Orgânica são poucas ou nenhumas, é apontado o professor que explica bem e o estudo como os grandes responsáveis.

No entanto, algumas das respostas dos alunos com o ES concluído pressupõem alguma reflexão. $11 \%$ dos alunos admitem ter «razoável» dificuldade apesar do professor explicar bem e a mesma percentagem sente essa dificuldade apesar de entender que o assunto é interessante. Estas respostas apontam para a necessidade de uma abordagem diferente dos conteúdos de Química Orgânica.

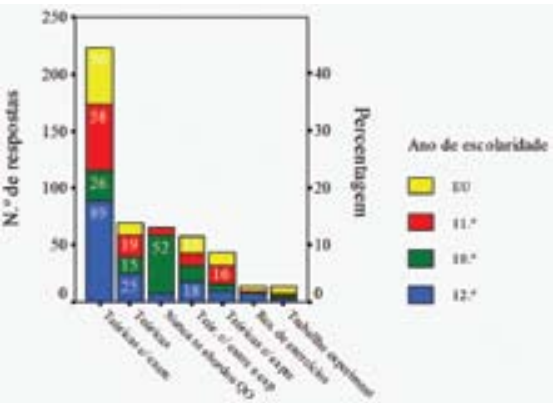

Gráfico 4 - Respostas à questão: "Que tipos de aulas é que os seus professores da área de Química habitualmente realizam ou realizaram na abordagem da Química Orgânica?"

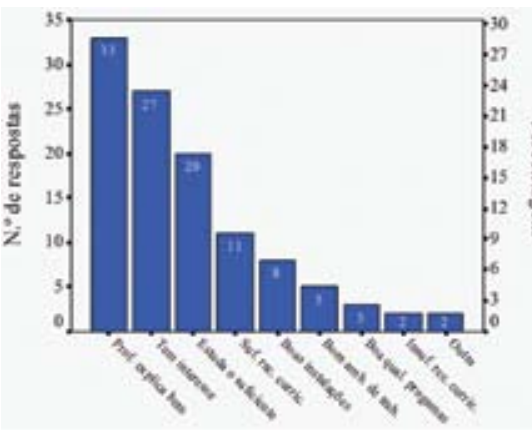

Gráfico 7 - Respostas apresentadas pelos $34 \%$ de alunos do ES inquiridos e que responderam sentir «Nenhuma ou muito pouca» dificuldade em compreender aspectos relacionados com a Química Orgânica

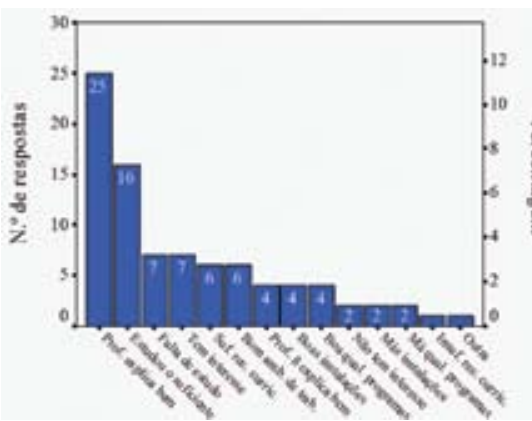

Gráfico 10 - Respostas apresentadas pelos $37 \%$ de alunos do $\mathrm{EU}$ inquiridos e que responderam sentir «Nenhuma ou muito pouca» dificuldade em compreender aspectos relacionados com a Química Orgânica

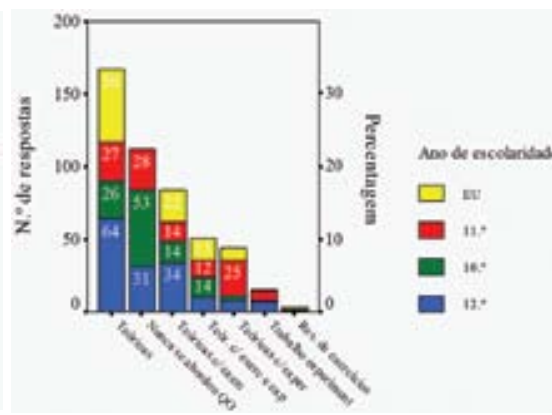

Gráfico 5 - Respostas à questão: "Que tipos de aulas é que os seus professores da área de Biologia habitualmente realizam ou realizaram na abordagem da Química Orgânica?"

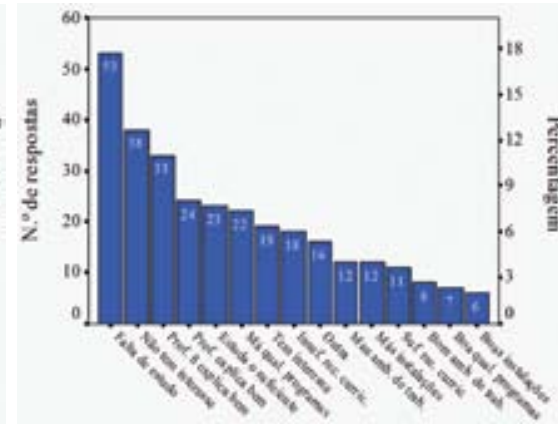

Gráfico 8 - Respostas apresentadas pelos $36 \%$ de alunos do ES inquiridos e que responderam sentir «Razoável» dificuldade em compreender aspectos relacionados com a Química Orgânica

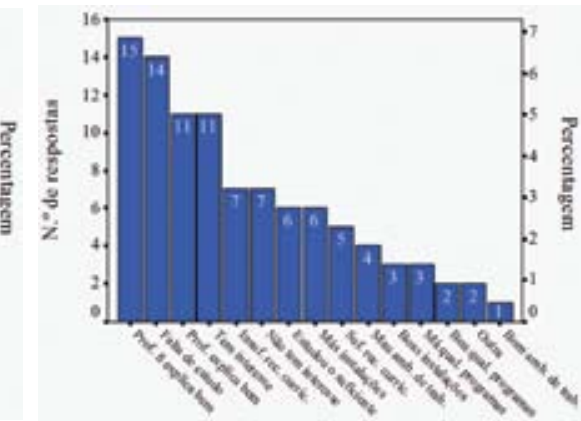

Gráfico 11 - Respostas apresentadas pelos $45 \%$ de alunos do EU inquiridos e que responderam sentir «Razoável» dificuldade em compreender aspectos relacionados com a Química Orgânica

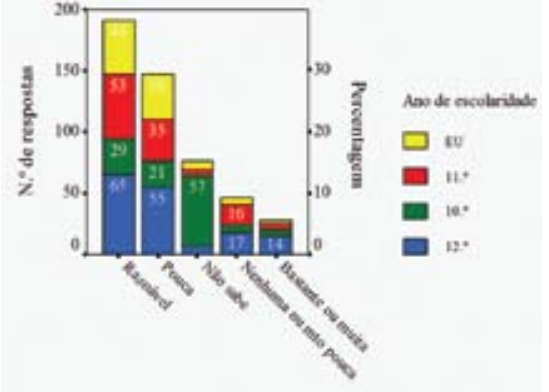

Relaçlo ano de escolaridade-guestio 10 parte II

Gráfico 6 - Respostas à questão: "Sente dificuldade em compreender aspectos relacionados com a Química Orgânica leccionados nas disciplinas das áreas de Química e/ou Biologia?"

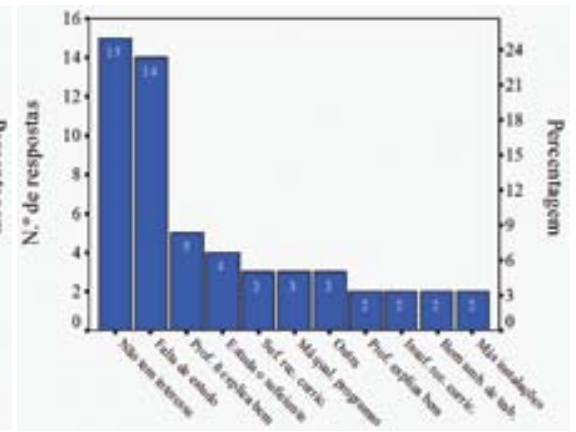

Gráfico 9 - Respostas apresentadas pelos $6 \%$ de alunos do ES inquiridos e que responderam sentir «Bastante ou muita» dificuldade em compreender aspectos relacionados com a Química Orgânica

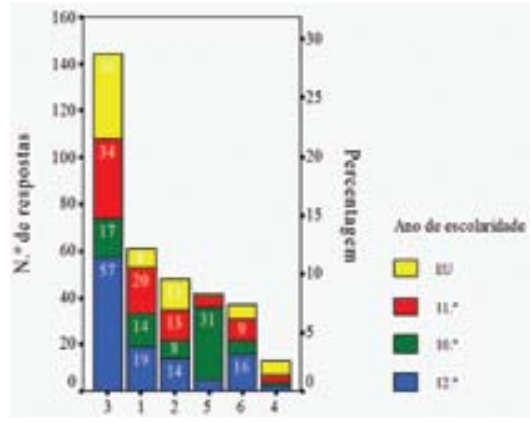

Gráfico 12 - Respostas apresentadas pelos alunos do ES e EU inquiridos à questão: "Como gostaria que fossem as aulas das áreas de Química e Biologia relativamente ao tópico Química Orgânica (conteúdos a estudar; forma de os leccionar pelo professor; recursos didácticos)?" 
No gráfico 12 estão representadas as respostas à questão aberta, obtidas pelos alunos do ES e EU, quando questionados sobre o tipo de aulas que gostariam de ter nas áreas de Química e Biologia relativamente ao a estudar; forma de os leccionar pelo professor; recursos didácticos). As respostas recolhidas foram categorizadas de acordo com as categorias apresentadas na Tabela 3.

Das seis categorias de respostas obtidas pelos alunos salienta-se que a categoria de resposta de código 4 é colocada apenas pela pertinência da mesma e não pelo número de respostas obtidas nesta categoria.

Como podemos constatar pelos resultados apresentados no gráfico 12 , a necessidade de maior componente prática nas aulas é a principal razão apontada pelos alunos dos vários níveis de ensino (29\%), $12 \%$ dos alunos gostaria de aulas mais diversificadas, mais dinâmicas e interactivas e uma percentagem semelhante gostaria de ter aulas teórico-práticas.

Verifica-se ainda que $8 \%$ dos alunos deste estudo referem não saber que tipo de aulas gostaria de ter, onde mais de $6 \%$ das respostas pertencem a alunos que frequentavam o $10 .^{\circ}$ ano de escolaridade.

\section{Conclusão}

Das respostas obtidas nos inquéritos por questionário aos alunos, verificouse que os alunos do $10 .^{\circ}$ ano de escolaridade consideram importante e interessante estudar Química Orgâtópico Química Orgânica (conteúdos

nica e encontram-se motivados para o seu estudo. Contudo, à medida que os alunos vão avançando no ensino formal vão perdendo a sua motivação e interesse para com esta área do saber. Tal constatação leva-nos à seguinte questão: "Será que os professores estarão a actuar mal?" Aparentemente esta situação está associada a uma desactualizada prática lectiva dos professores e com a forma como os próprios conteúdos de Química Orgânica se encontram reflectidos nos programas curriculares do ES [1, 2]. A prática lectiva que os professores referem utilizar na abordagem da Química Orgânica [1] não coaduna com a opinião dos alunos, apesar do presente estudo ter inquirido alunos e professores dos mesmos estabelecimentos de ensino.

Verificou-se ainda que as dificuldades sentidas pelos alunos estão directamente relacionadas com o seu grau de interesse e motivação. Os alunos propõem que as aulas com conteúdos de Química Orgânica deveriam recorrer a vários recursos didácticos, com especial destaque para as novas tecnologias e o trabalho laboratorial, de forma a tornar esta área da Química mais interessante e motivadora.

Os alunos que já concluíram o ES apontam o professor como principal causa do insucesso/dificuldades sentidas na Química Orgânica.

Apesar do estudo principal na aplicação dos inquéritos por questionário apenas se ter realizado em estabelecimentos de ensino do Centro de Área Educativa de Aveiro, pensa-se que os resultados do estudo deverão traduzir a realidade a nível Nacional.

Tabela 3 - Categorias de resposta e respectiva codificação para a questão: "Como gostaria que fossem as aulas das áreas de Química e Biologia relativamente ao tópico Química Orgânica (conteúdos a estudar; forma de os leccionar pelo professor; recursos didácticos)?"

\begin{tabular}{|c|l|}
\hline Código & \multicolumn{1}{c|}{ Categoria de resposta } \\
\hline 1 & $\begin{array}{l}\text { Os alunos indicam que gostariam que as aulas das áreas de Biologia e/ou Química } \\
\text { relativamente ao tópico Química Orgânica fossem originais, dinâmicas, interactivas e } \\
\text { recorressem a vários recursos didácticos }{ }^{3} \text {. }\end{array}$ \\
\hline 2 & $\begin{array}{l}\text { Os alunos indicam que gostariam que as aulas das áreas de Biologia e/ou Química } \\
\text { relativamente ao tópico Química Orgânica fossem teórico-práticas }\end{array}$ \\
\hline 3 & $\begin{array}{l}\text { Os alunos indicam que gostariam que as aulas das áreas de Biologia e/ou Química } \\
\text { relativamente ao tópico Química Orgânica fossem essencialmente práticas ou tivessem } \\
\text { maior componente prática }{ }^{5} \text {. }\end{array}$ \\
\hline 4 & $\begin{array}{l}\text { Os alunos indicam que gostariam que as aulas das áreas de Biologia e/ou Química } \\
\text { relativamente ao tópico Química Orgânica fossem dadas recorrendo a exemplos de } \\
\text { aplicação do tópico Química Orgânica no dia-a-dia. }\end{array}$ \\
\hline 5 & $\begin{array}{l}\text { Os alunos referem que não sabem como gostariam que fossem as aulas das áreas de } \\
\text { Biologia e/ou Química relativamente ao tópico Química Orgânica. }\end{array}$ \\
\hline 6 & Outros. \\
\hline
\end{tabular}

Sem pretender ser exaustivo nas conclusões que a análise dos resultados obtidos permite inferir, pode-se no entanto concluir que os resultados deste estudo apontam para a necessidade de intervenções, a diversos níveis, nomeadamente relacionadas com a revisão dos programas curriculares e dos manuais escolares do ES das áreas de Biologia e Química, bem como com a formação inicial e contínua dos professores deste nível de ensino. Para tal, é necessário adaptar as metodologias de ensino às novas exigências de aprendizagem da $\mathrm{Ci}$ ência, da Tecnologia, do Ambiente e das suas inter-relações com a Sociedade da Informação em que se vive nos dias de hoje, apostando em aulas diversificadas com maior componente laboratorial e com recurso às novas tecnologias da comunicação e informação.

\section{Notas}

1 Podem ser fornecidos a totalidade dos mesmos por solicitação aos autores deste estudo.

2 Incluíram-se nesta categoria respostas simples, tais como referir apenas que a Química Orgânica é a Química dos compostos de carbono, atendendo ao que normalmente é salientado nos manuais escolares do ES.

${ }^{3}$ Os recursos didácticos referidos pelos alunos são: apresentações em PowerPoint, trabalhos em grupo, realização de trabalho laboratorial, visitas de estudo, realização de exercícios, visualização de filmes e utilização de novas tecnologias.

${ }^{4}$ Entenda-se que aulas teórico-práticas são aulas teóricas com realização de trabalho laboratorial.

${ }^{5}$ Entenda-se que aulas práticas são aulas com realização de trabalho laboratorial.

\section{REFERÊNCIAS}

[1] S. Leal, J. P. Leal, M. A. F. Faustino, A. M. S. Silva, "A Química Orgânica no Ensino Secundário: A percepção dos Professores", Química 119 (2010) 49-54.

[2] S. Leal, A Química Orgânica no Ensino Secundário: percepções e propostas, Dissertação de mestrado inédita, Aveiro, 2006. 